\title{
Nos passos de Frei Tito
}

\section{Alfredo Bosi}

H Á BIOGRAFIAS e biografias. Há as que se limitam a arrumar linearmente alguns acontecimentos de uma vida considerados importantes: são crônicas feitas para fins didáticos ou jornalísticos. Outras pretendem descer ao subsolo das motivações do biografado: são exercícios psicológicos nos quais os documentos se misturam com hipóteses arriscadas e lances de ficção: biografias romanceadas que desejam virar best-sellers. Outras há ainda que, à força de aplicarem ao objeto esquemas ideologizantes, transformam-no em alegoria da sua época ou da classe a que pertencem: são obras que reduzem a pessoa a uma suposta média do seu contexto.

A nenhuma dessas categorias ajusta-se a biografia de Frei Tito de Alencar, esse "homem torturado" cujas vida, paixão e morte nos são contadas por Leneide Duarte-Plon e Clarisse Meireles em livro recentemente publicado. O que é dado ao leitor é a história de um religioso e militante socialista extraída de depoimentos de pessoas que o acompanharam de perto na luta contra a ditadura militar, ou (como se prefere dizer hoje) civil-militar, implantada em 1964. Não há nessa obra admirável, sóbria mas terrível, margem para especulações doutrinárias. Tudo é direto e vivo, como deve ser o testemunho de amigos e companheiros que perfilaram no perigo os mesmos valores e desejam ser fiéis à memória do grupo.

Quem são os depoentes que deram ao livro a sua matéria-prima? São dezenas, mas entre as testemunhas de maior relevo estão os frades próximos de Frei Tito no Convento Dominicano das Perdizes; o psicanalista Jean-Claude Rolland, que tratou dele nos últimos meses de sua vida; frei Xavier Plassat, fio condutor da memória do período em que Tito viveu na comunidade de Abresle, perto de Lyon; e Nildes de Alencar Lima, a irmã que o criou, como era hábito no seio das famílias numerosas do Ceará, em que as filhas mais velhas cuidavam dos menores como segundas mães. A esses nomes as autoras acrescentam os dos entrevistados, militantes que conheceram Tito ao longo dos anos de chumbo: um elenco que dá o perfil da resistência ao regime nos seus primeiros anos.

Tito de Alencar Lima nasceu em Fortaleza, em 14 de setembro de 1945, o mais novo dos quinze filhos de Ildefonso Rodrigues de Lima e Laura de Alencar Lima. Nesse mesmo ano em que se iniciava a democratização do país, o Partido Comunista Brasileiro entrava na legalidade elegendo Luiz Carlos Prestes como senador e Carlos Marighella como um dos quatorze deputados da legenda que integravam a Assembleia Nacional Constituinte. Em abril de 1947 o PCB caía na ilegalidade por um ato do governo Dutra. Os pais de Tito, embora católicos fervorosos, tinham apoiado naquela altura o candidato comunista à prefeitura de Fortaleza, Acrísio Moreira da Rocha.

Da infância Tito diria nos cadernos de exílio: "Quando secar o rio de minha infância, secará toda a dor". Frase que pode ser interpretada como prenúncio da morte que sobreviria quando cessasse toda memória de um tempo feliz. Ainda 
antes de decidir sua entrada para o seminário, o adolescente conheceu o momento de renovação da Igreja Católica. Uma ala progressista crescia e aproximava-se não só teórica, mas praticamente de agrupamentos de esquerda. Ele se filia, em 1962, à Juventude Estudantil Católica (JEC). Sua vocação religiosa o leva à Ordem dos Pregadores, vanguarda do reformismo estimulado por uma vigorosa corrente francesa de pensamento que o Concílio então absorvia. Não por acaso, um dos peritos em doutrina social do conclave era o padre Lebret cujo movimento Economia e Humanismo deitara raízes entre os dominicanos de São Paulo atraindo não poucos socialistas agnósticos. Era o primeiro passo de uma generosa aliança com todos os benefícios e riscos que o tempo iria trazer.

Em termos de política nacional ocorria a convergência de partidos de tendência social-democrática, como o PTB de Pasqualini e Brizola, com nacionalistas de vário espectro, socialistas históricos e alas pragmáticas do PCB em plena clandestinidade. Era uma animosa coalizão de centro-esquerda, que os puritanos universitários se compraziam em chamar populista. Levantavam-se as bandeiras de reforma agrária, reforma urbana, reforma política, reforma eleitoral. Os dominicanos das Perdizes, liderados por frei Carlos Josaphat, fundaram o jornal Brasil Urgente, que apoiava o programa das "reformas de base" do presidente João Goulart. O capítulo "A aliança de Marx com Cristo" traça um vivo retrato do que constituía o pensamento social da esquerda cristã nos anos 1960.

$\mathrm{O}$ engajamento de Frei Tito intensificou-se nos anos de formação como seminarista, a partir de 1965-1966. Depois de um primeiro momento de per- plexidade, alguns grupos de oposição clandestina se radicalizaram. Confiante no ardor revolucionário de alguns frades mais empenhados na luta contra o regime, Carlos Marighella, líder da Aliança Libertadora Nacional, pediu-lhes auxílio logístico para desencadear um movimento de resistência armada inspirado na guerrilha que culminara com a vitória da revolução cubana. A região escolhida, por ser também um ponto de apoio junto à pastoral dominicana, foi a de Conceição do Araguaia. O plano empolgou vários religiosos, mas as autoras colheram depoimentos que entremostram um Frei Tito simpático, mas ao mesmo tempo perplexo em face do que seria, de fato, uma desastrada aventura.

Retraído embora, o seu envolvimento foi de uma lealdade exemplar: a ele recorreram os dirigentes da União Estadual dos Estudantes (UNE) para a escolha de um lugar onde pudessem realizar o trigésimo Congresso da UNE, que se deu em outubro de 1968, em um sítio localizado em Ibiúna (SP), e terminou com a detenção de todos os participantes, incluindo Frei Tito e outros dominicanos. A partir desse momento, Frei Tito estaria na mira do Deops e de seus futuros torturadores comandados pelo delegado Sérgio Fleury.

A repressão pôde apertar o cerco com o instrumento legal que lhe daria, em dezembro de 1968, o AI-5. Suprimidas as instâncias da democracia representativa e até mesmo o recurso ao habeas corpus, os grupos radicais lançaram-se a um plano de guerrilha urbana, com sucessivas capturas de diplomatas estrangeiros realizadas com o intuito de obter a liberdade de presos políticos. Tito, preso na madrugada de 4 de novembro de 1969, dia em que Marighella seria morto, pas- 


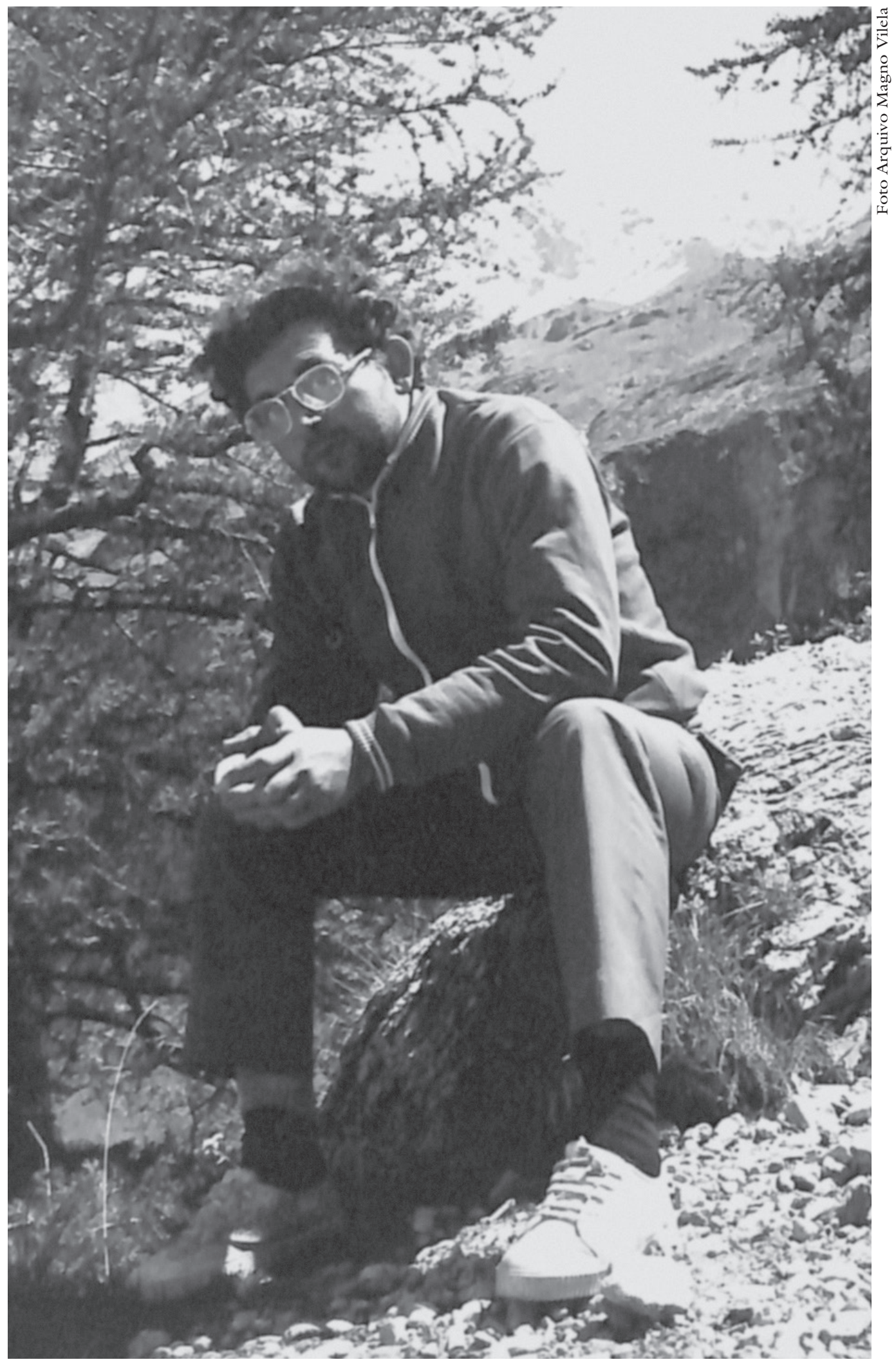

Frei Tito de Alencar (1945-1974), no Sul da França em 1974. 
saria pelo Deops, pelo Presídio Tiradentes e pelo inferno da Oban (depois Doi-Codi), onde foi barbaramente torturado. Tentou suicídio nessa ocasião. Foi oficialmente banido do Brasil em dezembro de 1970 quando os sequestradores do embaixador suíço Giovanni Enrico Bucher, liderados por Carlos Lamarca, exigiram a soltura de setenta presos políticos em troca da libertação do diplomata.

Do refúgio na França junto aos dominicanos de Paris e de Lyon até o suicídio em agosto de 1974 dão as autoras desse livro notícias colhidas de depoimentos de amigos e companheiros: frades, psicanalistas e numerosos exilados brasileiros. Trata-se de uma crônica bem articulada em que vemos Tito ora aproximar-se esperançoso, ora afastar-se deprimido dos militantes encorajados por grandes intelectuais franceses (como Sartre, que conclamou os brasileiros à luta armada contra a ditadura). Sobressaem as figuras do deputado cassado Márcio Moreira Alves e de Violeta Arraes (irmã de Miguel Arraes, então na Argélia), promotores da difusão de informações sobre torturas e mortes ao longo desses anos de chumbo. Tito aderia a essas expressões de resistência, sempre nos limites da sua condição psíquica, assediada pelos fantasmas dos torturadores, causa provável do suicídio.

Não cabe nesta resenha acompanhar o relato angustiante desses anos finais de uma vida ceifada tão cruelmente pelos esbirros do regime. Que os leitores se detenham nas transcrições de escritos de Frei Tito redigidos no exilio. Neles se exprimem as esperanças do militante e a confiança no surgimento de um novo cristianismo e de um Brasil livre e justo.

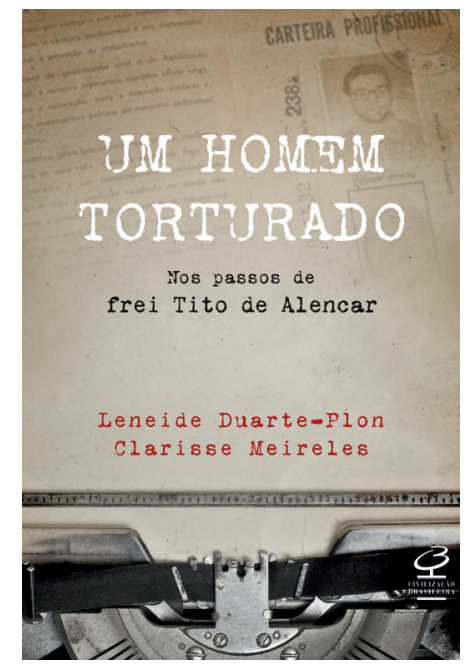

DUARTE-PLON, L.; MEIRELES, C. Um homem torturado. Nos passos de Frei Tito de Alencar. Prefácio de Vladimir Safatle.

Rio de Janeiro: Civilização Brasileira, 2014. 420p.

Alfredo Bosi é titular de Literatura Brasileira na Universidade de São Paulo e membro da Academia Brasileira de Letras. Publicou, entre outras obras, História concisa da literatura brasileira; $O$ ser e o tempo da poesia; Céu, inferno; Dialética da colonização; Machado de Assis: o enigma do olhar; Literatura e resistência; Brás Cubas em três versões; Ideologia e contraideologia; e Entre a literatura e a história. É editor da revista Estudos Avançados.

@-abosi@usp.br

I Faculdade de Filosofia, Letras e Ciências Humanas, Universidade de São Paulo, São Paulo/SP, Brasil. 